УДК 355.45

Катерина Олександрівна Сфанова

Зоя Миколаївна Пономаренко

Микола Олександрович Масесов

Військовий інститут телекомунікацій та інформатизацї, Київ, Украӥна

\title{
АКТУАЛЬНІСТЬ ВПРОВАДЖЕННЯ ТА ВИКОРИСТАННЯ MEPEЖI SDN
}

В статті представлено динаміку розвитку телекомунікаиійних мереж: ISDN $\rightarrow$ IP $\rightarrow$ ethernet, (конвергенцію телекомунікаційних технологій). Показано, щзо ключовою проблемою в телекомунікаційних мережах є проблема забезпечення якості обслуговування. Причому із зростанням різнорідності трафіку ия проблема стає все гостріше, вимагаючи серйозного та узгодженого опрацювання множсини мережних задач різних рівнів еталонної моделі взаємодії відкритих систем. У зв'язку із потребою у послугах якості обслуговування значну увагу приділяється створенню та розвитку програмно-конфігурованих мереж, які дозволяють вирішити існуючі проблеми в галузі телекомунікацій, а також наведені основні напрямки впровадження та використання мережі SDN.

У статті описується основний зміст та загальний стан проблеми та окремих задач щодо управління трафіком в мережі SDN, та вказується подальший напрямок ,щзодо їх вирішення

Ключові слова: $S D N$-мережа; трафік; рівень управління.

\section{Вступ}

Значний зріст об'ємів трафіку та зміна його структури, необхідність підтримки стрімкого росту кількості мобільних користувачів, формування високопродуктивних кластерів для обробки значного збільшення трафіку i добре масштабованих віртуалізованих середовищ для представлення хмарних сервісів - все це сприяло змінити вимоги до мережевих середовищ.

Постановка проблеми. Для обробки зростаючої кількості різнорідного трафіку, при існуючих технологіях транспортних мереж, необхідно нарощувати кількість різноманітного обладнання: комутатори i маршрутизатори, брандмауери (firewall), транслятори мережевих адрес, пристрої балансування навантаження, а також пристрої та системи забезпечення безпеки. Зазвичай мережеві адміністратори конфігурують кожен пристрій окремо, відповідно до мережевої топології i правил маршрутизації. Для цього використовуються інтерфейси конфігурації -для кожного пристрою і для кожного виробника, a іноді і для кожного пристрою однієї і тієї лінії виробництва одного виробника, хоча іноді використовують так званий «пакетний» метод конфігурації мережевих пристроїв. В цілому, такий підхід значно ускладнює модернізацію і розвиток мереж, впровадження інновацій, а також призводить до великої кількості капітальних і операційних витрат.

Аналіз останніх досліджень і публікацій [1-6] показав, що появою цифрових систем передачі почала розвиватися мережева концепція ISDN (Integrated Services Digita INetwork) - цифрова мережа 3 інтеграцією служби. Незважаючи на те, що при цьому спочатку передбачалося створення інтегральної мережі, що дозволяє надавати в рамках єдиної мережевої структури різні види послуг зв'язку, основним додатком залишилася послуга телефонії. Мережі ISDN передбачали використання цифрових систем передачі і цифрових вузлів комутації.

При цьому, для організації взаємодії апаратури вузлів комутації між собою i 3 тим, що підключається термінальним обладнанням були розроблені досить потужні системи сигналізації, що дозволяють передавати не тільки сигнальну інформацію, пов'язану з встановленням базового виклику, а й відомості, пов'язані 3 станом елементів мережі зв'язку, маршрутизації викликів, погодженням параметрів передачі і т.д.

3 появою Інтернету основними користувачами стали фізичні особи, що призвело до збільшення розгалуженості і підвищенню ємності мережі. В результаті виникла потреба в мережевій структурі, яка не поступається за своїми масштабним характеристикам телефонної мережі загального користування (ТМЗК). Однак використання двох паралельних мережевих структур 3 економічних i експлуатаційних показників було неефективним. Це зажадало розробки технологічних рішень, що забезпечують передачу різних видів інформації та надання різних видів послуг зв'язку в рамках єдиної мережевої структури.

В основі такого рішення повинен був лежати єдиний метод передачі інформації на основі комутації пакетів. Формування цього методу привело до появи мереж третього покоління мереж NGN (Next Generation Network), де в якості технічних засобів буде використовувати апаратно програмні засоби, орієнтовані на стек протоколів TCP / IP.

Таким чином, ідеологія NGN являє собою передачу будь-якої інформації в єдиній формі уявлення - IP-пакеті. Традиційні мережі не можуть підтримувати обмін трафіком в форматі IP. Цей факт має на увазі необхідність реконструкції всієї архітектури мережі: транспортної інфраструктури, рівня доступу і мережевий ієрархії. [2] 
Розвиток технологї Ethernet призвів до появи нового транспорту - PoS (Pocketover SDH / SONET),. По суті, це симбіоз двох добре знайомих технологій Ethernet i SDH / SONET. Така технологія має переваги системи передачі SDH, яка характеризується високою надійністю i керованістю мережі IP, що дозволяє надавати всі необхідні послуги передачі пакетного трафіку, включаючи такі додатки як VPN, VoIP i iн. Перспективним напрямком модернізації виглядає поступовий перехід до NGN за рахунок впровадження в традиційні мережі обладнання, здатного працювати з технологіями обох поколінь. Але тут виникла велика проблема, основу, якої становила пересилання даних i файлів, які не потребують особливих вимог до каналу, за винятком швидкості передачі даних, гостро виникли питання забезпечення якості сервісу (QoS), мінімальної затримки в каналі (latency) і ін.

Це, в першу чергу, пов'язано зі зміною структури призначеного для користувача трафіку, в якому стали переважати комунікації в реальному часі (Real Time Communications, RTC) - VoIP, відеосервіси тощо. У операторів виникла реальна потреба в динамічної пріорітезації трафіку. Наприклад, в деяких випадках пріоритет повинен бути зроблений для ftp-протоколу, в інших - для SIP і навпаки.

В результаті конфігурація великомасштабних мереж перетворюється на складне завдання i вимагає серйозних змін принципів побудови, експлуатації та управління мереж і управління ними.

Метою статті $\epsilon$ визначення актуальності впровадження та використання програмноконфігурованих мереж, рішень та задач, які вона вирішує.

\section{Викладення основного матеріалу}

Згідно щорічного прогнозу [1] з 2014 до 2017 об'єм мобільного трафіку зріс в 13 раз ісклав 11,2 ексабайтів в місяць, або 134 ексабайта в рік (один ексабайт дорівнює квінтильйону байт). Стійке зростання трафіку частково пояснюється збільшенням числа мобільних інтернетпідключень, кількість яких незабаром перевищить чисельність населення планети (за даними ООН, у 2017 році населення планети склало 7,6 млрд осіб).

134 ексабайта еквівалентні 30 трильйонів графічних файлів (по 10 картинок на кожного жителя планети щодня протягом року) або 3 трильйонів відеокліпів. На думку експертів [1] середньорічні темпи зростання споживчого та корпоративного сегменту використання трафіку, обумовлена наступними факторами:

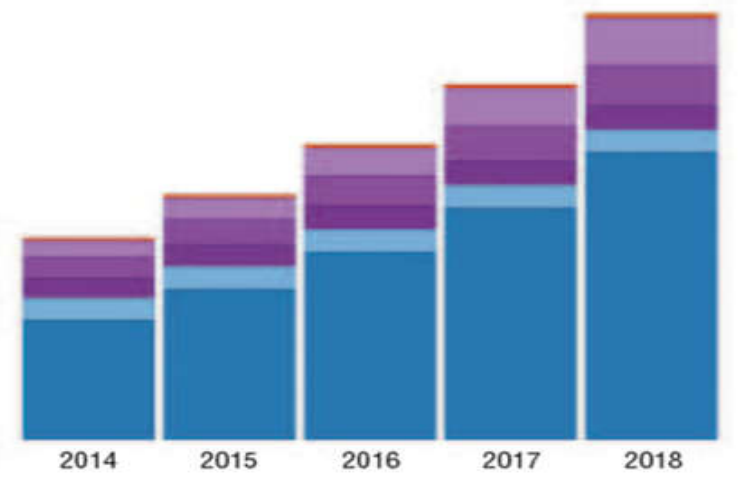

- Споживчий сегмент - відео

- Корпоративний сегмент-Web та передача інших даних

- Корпоративний сегмент - відео

n Споживчий сегмент - ігри он-лайн

- Споживчий сегмент - обмін файлами

- Споживчий сегмент - Web та передача інших даних

- Корпоративний сегмент обмін файлами

Рис.1 Графік споживчого та корпоративного сегменту використання трафіку

Зростання числа мобільних з'єднань. До 2018 року в світі буде налічуватися 10 млрд мобільних пристроїв, в тому числі 1,7 млрд з'єднань типу "машина-машина"(М2М) (в 2014 сукупна кількість мобільних пристроїв і міжмашинного з'єднань не перевищувало 7 млрд).

Зростання швидкості передачі даних. Середня швидкість передачі даних по мобільних мереж зросте в 7 разів - 3 1Мбіт / с у 2014 році до 3.9 Мбіт / с в 2017 році.

Зростання популярності відео. У 2017 року відео склало 66 відсотків загального мобільного трафіку (51 відсоток в 2014 році).

Вплив мобільних пристроїв / підключень:

Смартфони, ноутбуки та інші портативні пристрої у 2017 року згенерували 93 відсотки трафіку.

M2M-трафік (GPS-навігація, системи стеження, медичні програми) склав 5 відсотків від загального обсягу трафіку мобільних даних.

Ще 2 відсотки трафіку припадало на телефонні розмови.

У 2012 році тільки 14 відсотків пристроїв (1 млрд) могли працювати по протоколу IPv6. А вже у 2017 року число таких пристроїв збільшилось до 41 відсотка (4,2 млрд).

Швидкість мобільних мережевих з'єднань. Середня швидкість мобільних з'єднань з 2012 по 2017 pp. виросте в 7 разів. Цей показник став найважливішим фактором, що підтримує зростання обсягу мобільного трафіку.

Таблиияя. 1

Порівняльна характеристика швидкості з'єднання

\begin{tabular}{|l|c|c|c|c|c|c|c|}
\hline Кбіт/с & 2012 & 2013 & 2014 & 2015 & 2016 & 2017 & CAGR \\
\hline $\begin{array}{l}\text { Середня швидкість } \\
\text { мобільних з'єднань }\end{array}$ & 526 & 817 & 1233 & 1857 & 2725 & 3898 & $49 \%$ \\
\hline $\begin{array}{l}\text { Середня швидкість } \\
\text { 3'єднання в смартфонах }\end{array}$ & 2064 & 2664 & 3358 & 4263 & 5284 & 6528 & $26 \%$ \\
\hline
\end{tabular}


Очевидно, що впоратися з таким ростом трафіку можна двома способами:

Розширенням пропускної спроможності мережі за рахунок збільшення кількості апаратних мережевих вузлів і підвищенням їх потужності. Це призведе до значних капітальних i операційних затрат, проте досягнути бажаного результату так i не вийде, адже необхідність до нових послуг буде призводити до ще більш швидкого росту трафіку і інвестиційні плани операторів не встигатимуть за потребами послуг в трафіку.

Трансформація як самої мережі, так і всісї структурної моделі оператора. Таким чином, це дозволить вирішити проблему росту трафіку i потребу швидкого впровадження нових послуг, при цьому не збільшуючи фінансових затрат. Таким вимогам відповідає архітектура мережі, що основана на програмно-конфігурованій мережі SDN. Головна ідея SDN полягає у відділенні функцій передачі трафіку від функцій управління (включаючи контроль трафіку). У традиційних комутаторах i маршрутизаторах ці процеси невіддільні одна від одної і реалізовані в одній «коробці»: спеціальні мікросхеми забезпечують пересилання пакетів з одного порту на інший, проте в технології SDN процес розділення рівня управління та рівня передачі трафіку забезпечується за рахунок архітектури, котра складається 3 двох компонентів: одного або кількох комутаторів 3 підтримкою протоколу Openflow та $S D N$ контролера. (рис.2). Контролер являється одним із головних елементів програмно-визначених мереж, який виконує управління передачею трафіку через мережу, надсилаючи необхідні інструкції маршрутизаторам та комутаторам.

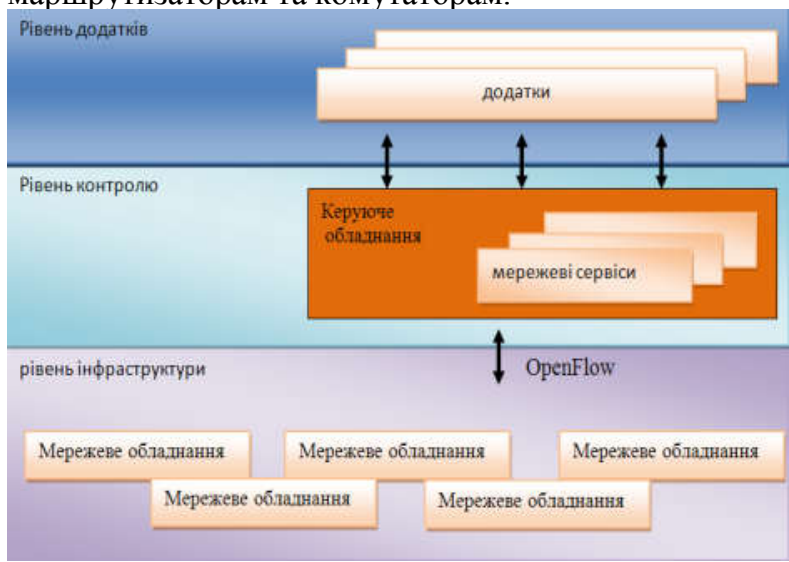

Рис.2.Архитектура SDN

Основним елементом концепції SDN-мереж $\epsilon$ протокол Open Flow. Відповідно, мережеве обладнання, яке працює на рівні інфраструктури повинне підтримувати архітектуру Open Flowкомутатора.

Комутатор Open Flow складається з однієї або декількох таблиць потоків (flow tables), групової таблиці (group table), які відповідають за пересилання пакетів та безпечного каналу (Secure Channel), що забезпечує передачу службової інформації між контролером i комутатором. Використовуючи протокол Open Flow контролер може здійснювати управління потоками вже за завчасно прописаним маршрутом, або в реальному масштабі часу, беручи до уваги навантраженість маршрутів. Таким чином, надаєтьсястандартний метод для програмування комутаторів без необхідності налаштування кожного комутатора окремо. Комутатор Open flow являє собою простий комутуючий елемент, який пересилає пакети між портами. Самі правила для комутації визначаються безпосередньо контролером.

Завдяки такій простоті управління технологія SDN стала ключовою технологією побудови мереж, котрі можуть розглядатися у трьох цільових напрямках.

1 напрямок- в мережі ЦОД [3].

При використанні технології SDN в ЦОДах вдається досягнути три основні результати: скорочення часу, виділення віртуальної інфраструктури та розгортання середовищ розробки і тестування;

оптимізація вкладень в фізичну ITінфраструктуру за рахунок більш активного використання принципів програмноконфігурованого ЦОДа (SD-DC) [3].

2 напрямок-у мережі операторів зв'язку [6].

3 напрямок - побудова багатофіліальних розподілених корпоративних мереж. (SD-WAN)

Якщо раніше для підключення нового елемента до корпоративної мережі зв'язку могли знадобитися місяці, то зараз досить встановити пристрій на об'єкт (нового елемента) і підключити його до мережі: автоматично будуть проведені всі необхідні налаштування i підключення всіх необхідних мережевих сервісів.

\section{Висновки й перспективи подальших досліджень}

Наведений в статті аналіз дозволяє відзначити актуальність архітектури SDN-мереж та виділити іï відносно традиційних,існуючих мереж за рахунок наступних переваг:

Глибока інтеграція. Кожний веб-сервіс може направити вимоги до пропускної спроможності до контролера, який відповідає за виконання запиту.

Зменшення вартості розгортання мереж. Проектування і виготовлення пристроїв 3 фіксованим налаштуванням (без необхідності оновлень)

Використання більш простих алгоритмів. Замість того, покладатись на алгоритм взаємодії між пристроями, можна використовувати більш простіші алгоритми.

Можливість розробки та розвитку мережевих програмних модулів. ПКС-контролер має інтерфейси API, котрі можуть використовуватись додатками.

Глобальна оптимізація і планування. Контролер посилається на глобальне представлення про мережу, тим самим використання мережевих ресурсів може стати більш раціональним, а також масштабованість мережі стає простіше .

Відкритість протоколу OpenFlow, що дозволяє позбутися залежності від виробника мережевих пристроїв.

Зручність адміністрування та налаштування.

Такі можливості до розширення в мережі SDN дозволять будувати реальні «хмари», масштабованість яких залежить від задач. При тому Modern Information Technologies in the Sphere of Security and Defence № 2(32)/2018 ISSSV2311-7249(Print)/ISSSV2410-7336(Onfine) $\quad 149$ 
мережа має потрібну інтелектуальність необхідну для ефективного управління мереж 3 великою

\section{Лimepamypa}

1. Результаты испытания скорости мирового Интернета (Cisco Global Internet Speed Test, GIST), проведенного в рамках программы Cisco VNI, и других независимых оценок сетевых скоростей. 2. Марціленко С.B. Застосування програмно-визначуваних мереж (SDN) в технології 5G / Марціленко С.В., Глоба Л.С. // Десята міжнародна науково-технічна конференція "Проблеми телекомунікацій” - Київ,Україна, 2016. - с. 191 - 194 3. Роговой В.П. сети Центры обработки данных на базе технологии SDN / Роговой В.П. // Десята міжнародна науково-технічна конференція "Проблеми телекомунікацій” - Київ,Україна, 2016. - с. 182 - 185. кількістю вузлів.

4. Журнал сетевых решений/LAN 2012 -2017. 5. А. Tootoonchian, Y. Ganjali. HyperFlow: A Distributed Control Planefo OpenFlow. In Proc. INM/WREN, San Jose, CA, April 2010. 6. Лурджан, М.Б. Використання програмноконфігурованих мереж для балансування навантаження в транспортних мережах операторів зв'язку / М.Б. Лурджан, А.А. Воропаева // Наукові праці Донецького національного технічного університету. Серія: Обчислювальна техніка та автоматизація.

Красноармійськ, ДонНТУ, 2016. Випуск 1 (28). - С. 87 95.

\title{
АКТУАЛЬНІСТЬ ВПРОВАДЖЕННЯ ТА ВИКОРИСТАННЯ MEPEЖI SDN
}

\author{
Екатерина Александровна Ефанова \\ Зоя Николаевна Пономаренко \\ Николай Александрович Масесов
}

\section{Военный институт телекоммуникаций и информатизации, Киев, Украина}

В статье представлена динамика развития телекоммуникационных сетей: ISDN $\rightarrow$ IP $\rightarrow$ ethernet, (конвергенцию телекоммуникационных технологий). Показано, что ключевой проблемой 8 телекоммуникационных сетях является проблема обеспечения качества обслужсивания. Причем с ростом разнородности трафика эта проблема становится все острее, требуя серьезной и согласованной обработки множества сетевых задач различных уровней эталонной модели взаимодействия открытых систем. В связи с необходимостью в услугах качества обслуживания значительное внимание уделяется созданию и развитию программно-конфигурируемых сетей. Которые позволяют решить существующие проблемы в области телекоммуникаций, а также приведены основные направления внедрения и использования сети SDN.

В статье описывается основное содержание и общее состояние проблемы и отдельных задач по управлению трафиком в сети SDN, и указывается дальнейшее направление, по их решению.

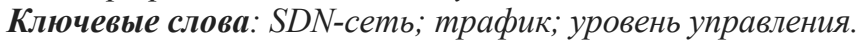

\section{RELEVANCE OF IMPLEMENTATION AND USING SDN NETWORK}

\author{
Kateryna A. Yefanova \\ Zoya M. Ponomarenko \\ Mykola O. Masesov
}

\section{Military Institute of Telecommunications and Informatization, Kyiv, Ukraine}

The article presents the dynamics of the development of telecommunication networks: ISDN $\rightarrow I P \rightarrow$ ethernet, (convergence of telecommunication technologies). It has been shown that the key problem in telecommunication networks is the problem of quality of service provision. Moreover, with the increasing heterogeneity of traffic, this problem becomes more acute, requiring a serious and consistent processing of a variety of network tasks of various levels of the reference model of interaction of open systems. In connection with the need for quality service, a great deal of attention is paid to the creation and development of softwareconfigurable networks, which allow to solve existing problems in the field of telecommunications, as well as the main directions of implementation and use of the SDN network.

The article describes the main content and general state of the problem and individual tasks for managing traffic in the SDN network, and indicates the further direction by their solution.

Key words: SDN-network; traffic; management level.

\section{References}

1. Cisco Global Internet Speed Test, GIST Scientific and Technical Conference "Telecommunication 2. Martsilenko S.V. (2016) The programmed-tagging measure Problems" Kiew $182-185$ p. 4. Network Solutions Journal $(\mathrm{SDN})$ in the technology $5 \mathrm{G}$ [Zastosuvannya prohramno- LAN 2012 -2017. 5. A. Tootoonchian, Y. Ganjali. Hyper vyznachuvanykh merezh (SDN) v tekhnolohiyi 5G] X Flow: A Distributed Control Planefo OpenFlow. In Proc. International Scientific and Technical Conference INM/WREN, San Jose, CA, April 2010. 6. Lurjan, M.B. "Telecommunication Problems" Kiew 191 - 194p. 3. Rogovoy (2016) Use of software-configurable networks for balancing V.P. (2016) Data center based on SDN technology Десята the load in transport networks of communication operators. міжнародна науково-технічна конференція [Tsentry Krasnoarmeysk N 1 (28), $87-95$ p. obrabotki dannykh na baze tekhnologii SDN] X International 